American J. of Engineering and Applied Sciences 3 (2): 372-379, 2010

ISSN 1941-7020

(C) 2010 Science Publications

\title{
Effect of Size of Heated Obstruction within Room on Three Dimensional Air Flow Characteristics
}

\author{
Abduljabbar Muttair Ahmed, Mukhtar Ahmad and Abdur Rahim \\ Department of Mechanical Engineering Faculty of Engineering and Technology, \\ Jamia Millia Islamia, New Delhi-110025, India
}

\begin{abstract}
Problem statement: This study reported a numerical investigation of three-dimensional turbulent buoyant recirculating flow within a room with heated obstruction. Approach: The study involved the solution of partial differential equations for the conservation of mass, momentum, energy, concentration, turbulent energy and its dissipation rate. These equations were solved together with algebraic expressions for the turbulent viscosity and the heat diffusivity, using k- $\varepsilon$ turbulence model. Results: The present study demonstrated the flow behavior, thermal distribution and $\mathrm{CO}_{2}$ concentration inside the room in the presence of heat flux obstruction with respect to three sizes of obstruction. Conclusion: The energy usage coefficient (efficiency of ventilation) increases with decrease in size of obstruction. Concentration of $\mathrm{CO}_{2}$ is very often used as an indicator for the control of air flow rate to the building. For the largest size of obstruction, the concentration of $\mathrm{CO}_{2}$ is maximum above the obstruction and reduces with the reduction in the size of the obstruction.
\end{abstract}

Key words: Concentration of $\mathrm{CO}_{2}$, efficiency of ventilation (Thermal), velocity distribution, temperature contour, Computational Fluid Dynamics (CFD)

\section{INTRODUCTION}

Air-conditioning is a process that simultaneously conditions air; distributes it combined with the outdoor air to the conditioned space; and at the same time controls and maintains the required space's temperature, humidity, air movement, air cleanliness, sound level and pressure differential within predetermined limits for the health and comfort of the occupants (Wang and Lavan, 1999). Moureh and Flick (2005) carried out experiments and numerical simulations in order to characterize velocities and airflow patterns within a long and empty slot-ventilated enclosure characterized by the presence of inlet and outlet sections on the same side at the front. Ventilation is defined as "controlled supply and exhaust of air to improve the indoor air quality". There are four different ventilation principles used to control the air distribution within ventilated rooms namely, unidirectional flow ventilation, mixing ventilation, displacement ventilation and local exhaust ventilation (Zou Yue, 1999). Recent researches turned their efforts towards finding an alternative approach based on the numerical solution of the governing flow equations for mass, momentum and scalar properties. This is because recent advances in numerical calculation procedures for fluid flow and heat transfer have brought computer usage within reasonable cost limits for practical design problems. Craven and Settles (2006) applied experimental velocity measurements by using particle image velocimetry PIV and a computational fluid dynamics CFD simulation was performed of the human thermal plume in a standard room environment with moderate thermal stratification. The effects of thermal stratification on the plume were explored via comparison with the results of a CFD simulation in a uniform environment Gosman et al. (1980) carried out measurement and calculation properties relevant to the flow in ventilated rooms. The measurements were obtained by laser-Doppler anemometry in a small-scale model room with a single square inlet. The calculations made use of a numerical procedure which solves, in finite-difference form, the elliptic partial-differential equations for three components of velocity, the pressure, the turbulence energy and its dissipation rate. Calculated results are shown to be in close agreement with the present measurements and with other available experimental data. Awbi (1989) applied a numerical solution to predict the air movement in square plan room ventilated by a continuous slot diffuser across the width of the ceiling and at a distance $1.2 \mathrm{~m}$ from a wall discharging towards the far wall. Two-dimensional

Corresponding Author: Abduljabbar Muttair Ahmed, Department of Mechanical Engineering,

Faculty of Engineering and Technology, Jamia Millia Islamia, New Delhi-110025, India 
non-isothermal solutions were used and this produced realistic predictions of the vertical velocity and temperature profiles when compared with measurements in the room. Rees and McGuirk (2002) used displacement ventilation room in conjunction with chilled ceiling panels. Complex lateral oscillations are seen in the plumes above the heat source which impinges on the ceiling and induced significant recirculating flows in room. Calculations show good agreement with those of experimental results. The indoor air flow and contaminant particle concentration in the two different rooms have been investigated by Tain et al. (2007) using the large eddy simulation. The first room is without contaminant and the second with contaminant. A good agreement is achieved between the predicted and measured data.

\section{MATERAILS AND METHODS}

THE general form of the (PDE'S): The equations to be solved could be expressed in the general form (Hadidi, 1998):

$$
\frac{\partial}{\partial X_{i}}\left(\rho \Phi U_{i}\right)=\frac{\partial}{\partial X_{i}}\left(\Gamma_{\Phi} \frac{\partial \Phi}{\partial X_{i}}\right)+S_{\Phi}
$$

Where:

$$
\begin{array}{ll}
\frac{\partial}{\partial X_{i}}\left(\rho \Phi U_{i}\right) & =\text { Convection term } \\
\frac{\partial}{\partial X_{i}}\left(\Gamma_{\Phi} \frac{\partial \Phi}{\partial X_{i}}\right) & =\text { Diffusion term } \\
S_{\Phi} & =\text { Source term } \\
\Phi & =\text { The dependent variable }
\end{array}
$$

Table 1 gives the expressions for the source terms $\mathrm{S}_{\mathrm{\Phi}}$ for each variable that is likely to be needed in solving ventilation problems.

Table 1: Diffusion coefficients and source for each variable

\begin{tabular}{llll}
\hline Equation & $\Phi$ & $\Gamma_{\Phi}$ & $\mathrm{S}_{\Phi}$ \\
\hline Continuity & 1 & 0 & 0 \\
Momentum & $\mathrm{U}$ & $\mu$ & $-\mathrm{p}_{\mathrm{x}}+1 / 3(\mu \nabla \cdot \mathrm{U})+\rho \mathrm{g}_{\mathrm{x}}$ \\
Momentum & $\mathrm{V}$ & $\mu$ & $\begin{array}{l}-\mathrm{p}_{\mathrm{y}}+1 / 3(\mu \nabla \cdot \mathrm{U})+ \\
\rho \beta\left(\mathrm{T}-\mathrm{T}_{\mathrm{ref}}\right) \mathrm{g}_{\mathrm{y}}\end{array}$ \\
Momentum & $\mathrm{W}$ & $\mu$ & $-\mathrm{p}_{\mathrm{z}}+1 / 3(\mu \nabla \cdot \mathrm{U})+\rho \mathrm{g}_{\mathrm{z}}$ \\
Temperature & $\mathrm{T}$ & $\Gamma$ & $\frac{\mathrm{q}}{\mathrm{C}_{\mathrm{p}}}$ \\
Concentration & $\mathrm{C}$ & $\Gamma$ & $\rho \mathrm{c}$ \\
\hline
\end{tabular}

Turbulence model: In the present study the $\mathrm{k}-\varepsilon$ turbulence model has been used. The (PDE) for the turbulent kinetic energy $\mathrm{k}$ and its dissipation rate $\varepsilon$ are as follows:

$$
\begin{gathered}
\frac{\partial}{\partial X_{i}}\left[\rho U_{i} k-\left(\mu+\frac{\mu_{t}}{\sigma_{k}}\right) \frac{\partial k}{\partial X_{i}}\right]=G_{k}+G_{B}-\rho \varepsilon \\
\frac{\partial}{\partial X_{i}}\left[\rho U_{i} \varepsilon-\left(\mu+\frac{\mu_{t}}{\sigma_{\varepsilon}}\right) \frac{\partial \varepsilon}{\partial X_{i}}\right]=\frac{\varepsilon}{k}\left[C_{1}\left(G_{k}+G_{B}\right)-C_{2} \rho \varepsilon\right]
\end{gathered}
$$

where, $\sigma_{\mathrm{k}}$ and $\sigma_{\varepsilon}$ are turbulent Prandtl number for $\mathrm{k}$ and $\varepsilon$ :

$$
\begin{gathered}
G_{k}=\mu_{t}\left[\frac{\partial U_{i}}{\partial X_{j}}+\frac{\partial U_{j}}{\partial X_{i}}\right] \frac{\partial U_{i}}{\partial X_{j}} \equiv \text { Kinetic energy } \\
\text { generation by shear } \\
G_{B}=-\frac{\mu_{t} g \beta}{\sigma_{t}} \frac{\partial T}{\partial y} \equiv \text { Kinetic energy generation by buoyancy }
\end{gathered}
$$

Where:

$\beta=$ The thermal expansion coefficient

$\mathrm{g}=$ The gravitational acceleration.

The turbulent viscosity $\mu_{\mathrm{t}}$ can now be calculated from the values of $\mathrm{k}$ and $\varepsilon$ :

$$
\mu_{\mathrm{t}}=\mathrm{C}_{\mu} \frac{\mathrm{k}^{2}}{\varepsilon}
$$

where, $\mathrm{C}_{1}, \mathrm{C}_{2}, \mathrm{C}_{\mu}$ are the turbulence model constant given by (Fluent Inc., 2006):

$$
\begin{array}{ccccc}
\mathrm{C}_{\mu} & \mathrm{C}_{1} & \mathrm{C}_{2} & \sigma_{\mathrm{k}} & \sigma_{\varepsilon} \\
0.09 & 1.44 & 1.92 & 1.0 & 1.3
\end{array}
$$

Numerical solution procedure: The computations were performed using Fluent Inc. (2006) under steadystate conditions by solving equations of the conservation of mass, momentum, energy and concentrations. Pre processing requires the construction of geometry and generation of the mesh on the surfaces or volumes. This is done with the software gambit, linked to Fluent. Before starting a simulation the physical models have to be tackled. This includes the choice of incompressibility, viscosity and definition of boundary condition. The transport equations are discretized using the finite volume method. The central differencing scheme is used to approximate the convective terms at the faces of the control volumes. The SIMPLE algorithm is employed as the pressure-velocity coupling method. 

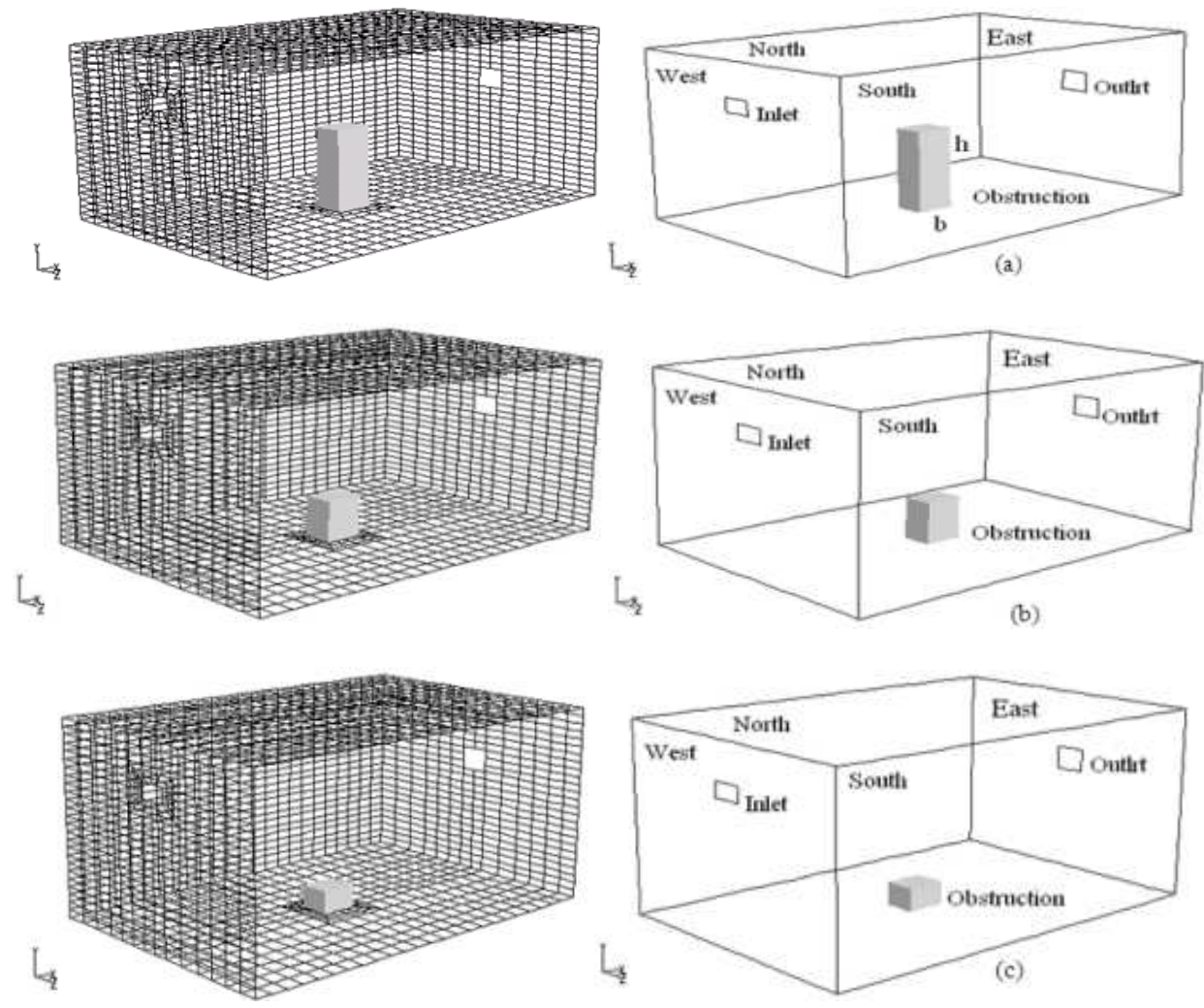

Fig. 1: Schematic of the room and mesh employed for the solution of ventilated room with heated obstruction at (a) $\mathrm{b} / \mathrm{h}=0.42 ;(\mathrm{b}) \mathrm{b} / \mathrm{h}=0.83 ;$ (c) $\mathrm{b} / \mathrm{h}=1.66$

The convergence criteria for the solution velocities, pressure, concentration and energy are $10^{-6}$. For post processing analysis of the results, there are number of choices available for the presentation of the results. Namely: contours, $\mathrm{x}-\mathrm{y}$ plots, velocity vectors and path lines. Through these available choices several variables can be analyzed like velocity, temperature, turbulence, density and many more.

The geometry considered and boundary conditions: The geometrical arrangement of room that has been tested in the present work has dimensions of $(5.4 \times 2.5 \times 3.6 \mathrm{~m}) \quad(\mathrm{L} \times \mathrm{H} \times \mathrm{W})$. The dimension of the obstruction and the coordinate positions of their centers are listed in (Table 2). The Schematic of the room and computational grid employed for the present solution of ventilated room with different size of a heated obstruction is shown in (Fig. 1). The sizes of obstruction, value of volume flow rate, temperature at inlet and the metabolic rate of obstruction as standing activity (Awbi, 1991) are given in Table 3.
Table 2: Dimension and position of objects in the ventilated room

\begin{tabular}{lll}
\hline Object & Size m & Position $(\mathrm{x}, \mathrm{y}, \mathrm{z}) \mathrm{m}$ \\
\hline Inlet & $0.2(\mathrm{~L}) \times 0.4(\mathrm{~W})$ & $0,1.8,0.6$ \\
Exhaust & $0.3(\mathrm{~L}) \times 0.4(\mathrm{~W})$ & $5.4,1.4,1.6$ \\
& $0.5(\mathrm{~b}) \times 1.2(\mathrm{~h}) \times 0.4(\mathrm{w})$ & \\
Obstruction & $0.5(\mathrm{~b}) \times 0.6(\mathrm{~h}) \times 0.4(\mathrm{w})$ & $2.45,1.6$ on the floor \\
& $0.5(\mathrm{~b}) \times 0.3(\mathrm{~h}) \times 0.4(\mathrm{w})$ & \\
\hline
\end{tabular}

Table 3: Values size of obstruction, flow rate and metabolic rate for ventilated room

\begin{tabular}{lllll}
\hline Case & $\begin{array}{l}\text { Size of } \\
\text { obstruction } \mathrm{b} / \mathrm{h}\end{array}$ & $\begin{array}{l}\text { Air flow } \\
\text { rate } \mathrm{m}^{3} \mathrm{~min}^{-1}\end{array}$ & $\begin{array}{l}\text { Inlet } \\
\text { temperature } \mathrm{K}\end{array}$ & $\begin{array}{l}\text { Metabolic } \\
\text { rate } \mathrm{w} \mathrm{m}^{-2}\end{array}$ \\
\hline 1 & 0.42 & & & \\
2 & 0.83 & 14.7 & 293 & 116 \\
3 & 1.66 & & & \\
\hline
\end{tabular}

\section{RESULTS}

Air flow pattern: The computed distributions of vector and streamlines in the room are illustrated in (Fig. 2a) for case 1 (size of obstruction $\mathrm{b} / \mathrm{h}=0.42$ ). It is observed that the cold air enters horizontally, moves straight and reaches to the east wall. Air flow strikes the east wall and bends downwards to form recirculation zone between the obstruction and the wall. 

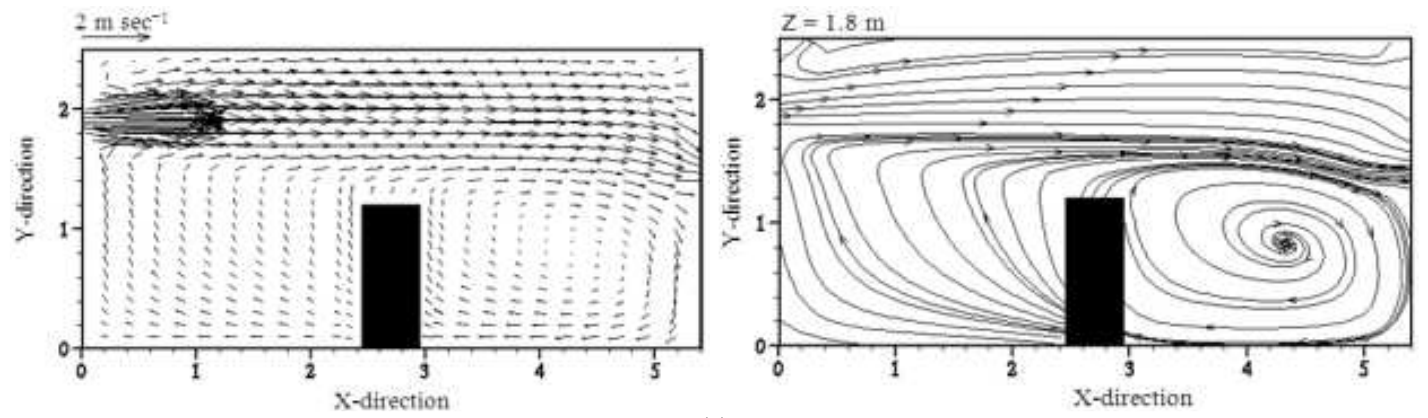

(a)
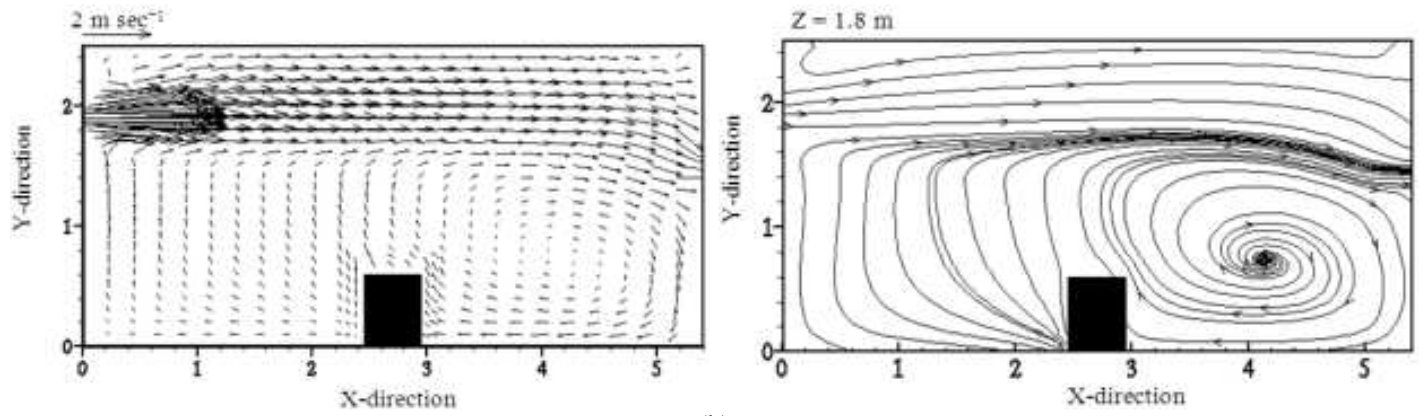

(b)
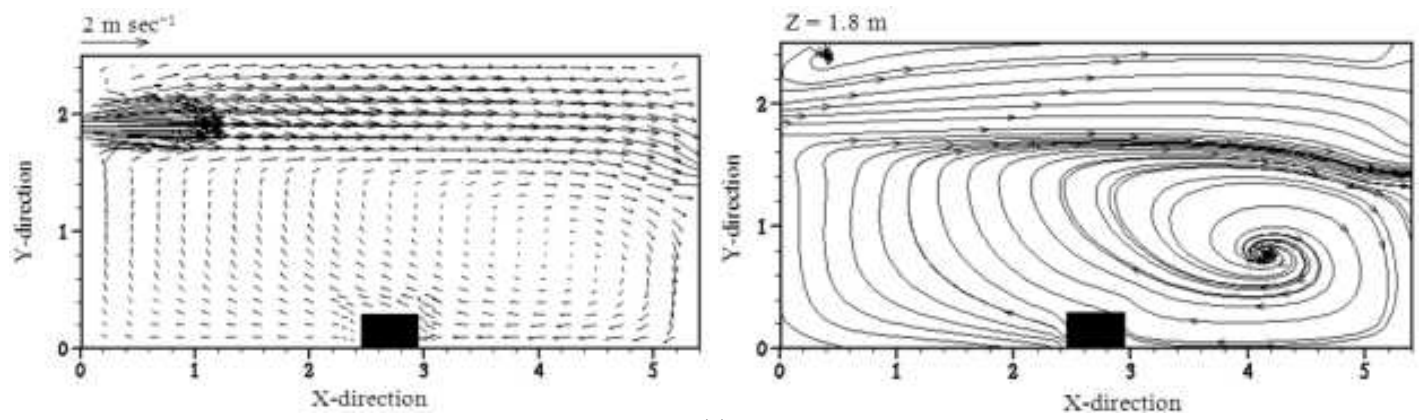

(c)

Fig. 2: Velocity vector and stream-lines showing the air flow patterns in $x-y$ plane at $Z=1.8 \mathrm{~m}$ (a) case $-1, b / h=$ 0.42 ; (b) case $-2, \mathrm{~b} / \mathrm{h}=0.83$; (c) case $3, \mathrm{~b} / \mathrm{h}=1.66$

Velocity of The air at inlet $(2 \mathrm{~m} / \mathrm{sec})$ is reduced and reaches to the minimum value at the stagnation point in the center of recirculation zone. It can be seen from (Fig. 2b) for case -2 the size of obstruction reduces to $\mathrm{b} / \mathrm{h}=0.83$. The recirculation zone is formed between the left face of obstruction and the east wall and the recirculation zone extends to upward of obstruction. (Fig. 2c) shows the minimum size of obstruction for case-3 $(\mathrm{b} / \mathrm{h}=1.66)$. Air flow strikes east wall and bends downward to traverse obstruction. The flow reaches to the west wall and forms large recirculation zone, this is due to reduced size of obstruction. Center of large recirculation zone is at the same position as in the pervious two cases. Maximum value of velocity for all three cases occurs near the opening inlet due to the jet of ventilation and constant air flow rate.

Temperature distribution: The temperature of the inflow air in the room is $293 \mathrm{~K}$ and that of the obstruction is $300 \mathrm{~K}$ at metabolic rate $116 \mathrm{~W} \mathrm{~m}^{-2}$. (Fig. 3) shows temperature distribution in $x-y$ plane at $Z$ $=1.8 \mathrm{~m}$ with respect to three sizes of obstruction. (Fig. 3a) show temperature contour for the size of obstruction $\mathrm{b} / \mathrm{h}=0.42$. Cold air jet passes above the obstruction and strikes the east wall to form recirculation zone at low temperature while the zone near left face of obstruction remains unaffected. (Fig. 7b) shows the contour of temperature at size of obstruction $\mathrm{b} / \mathrm{h}=0.83$. 


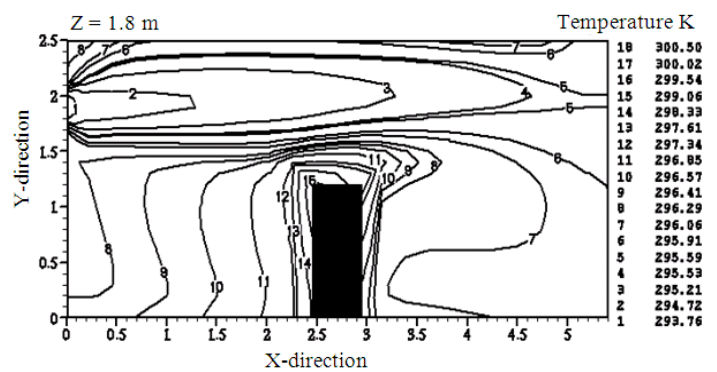

(a)

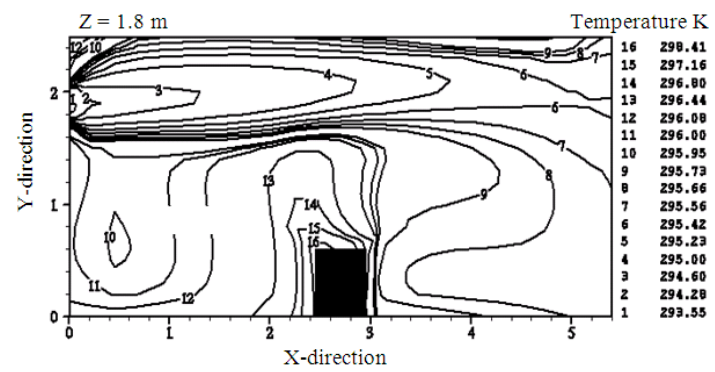

(b)

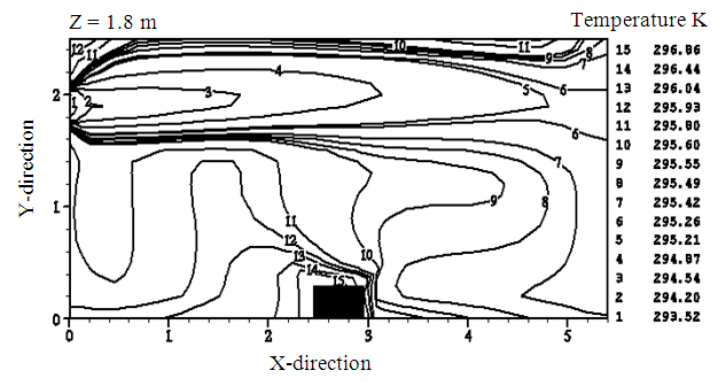

(c)

Fig. 3: Temperature contour showing the variation of temperature in $\mathrm{x}-\mathrm{y}$ plane at $\mathrm{Z}=1.8 \mathrm{~m}$ (a) case$1, \mathrm{~b} / \mathrm{h}=0.42$ (b) case $-2, \mathrm{~b} / \mathrm{h}=0.83$ (c) case- 3 , $\mathrm{b} / \mathrm{h}=1.66$

The jet of cold air reaches east wall and thus causes reduction in the temperature in the zone between west wall of room and the left face of obstruction. The zone between the left face of obstruction and west wall of room remains still unaffected. (Fig. 3c) shows retrogression effect of obstruction due to reduced size of obstruction $\mathrm{b} / \mathrm{h}=1.66$. Jet of cold air reaches to east wall and forms recirculation zone with low temperature. The effect of obstruction seen is less than those in the previous cases due to reduction in size of obstruction.

Effect of size of obstruction on Nuesselt number: The local Nusselt number is defined as:

$$
\mathrm{Nu}=\frac{\mathrm{h}_{\mathrm{cx}} \cdot \mathrm{x}}{\mathrm{k}_{\mathrm{c}}}
$$

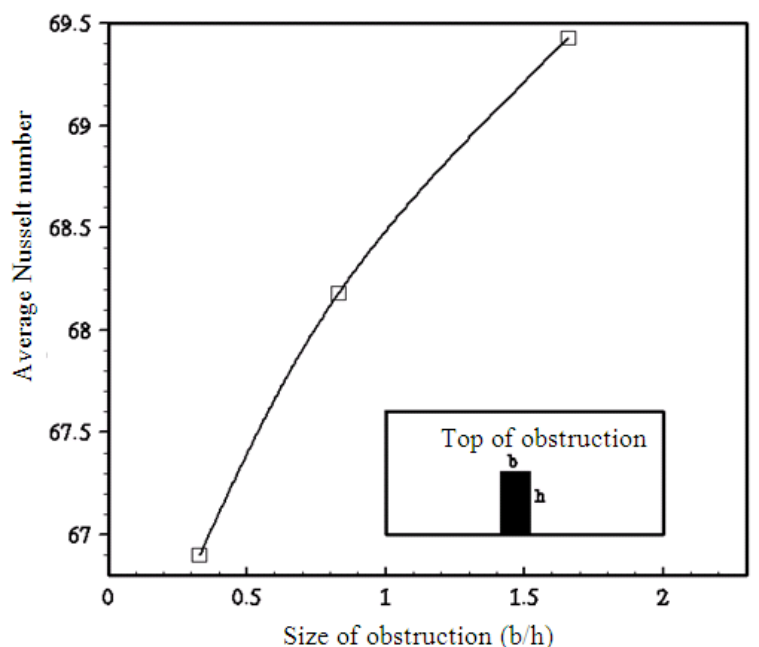

Fig. 4: Average Nusselt number on the top face of obstruction at three values of size of obstruction

where, $h_{c x}$ is the local heat transfer coefficient in turbulent flow over a plane surface (Chen and Cheng, 2006):

$$
\mathrm{h}_{\mathrm{cx}}=\frac{\left.\mathrm{k}_{\mathrm{c}}(\partial \mathrm{T} / \partial \mathrm{y})\right|_{\mathrm{w}}}{\left(\mathrm{T}_{\mathrm{w}}-\mathrm{T}_{\mathrm{m}}\right)}
$$

Based on the results of the local Nusselt number, average Nusselt number on top face of obstruction can be determined by the expression:

$$
\overline{\mathrm{Nu}}=\left.\frac{1}{\left(\mathrm{~T}_{\mathrm{w}}-\mathrm{T}_{\mathrm{m}}\right)} \int_{0}^{\mathrm{L}}(\partial \mathrm{T} / \partial \mathrm{y})\right|_{\mathrm{w}} \mathrm{dx}
$$

Average Nusselt number on the top face of obstruction for three cases is shown in Fig. 4. Nusselt number is increasing with decrease in size of obstruction due to decrease in the temperature difference between the top face of obstruction and mean temperature.

Distribution and concentration of $\mathbf{C O}_{2}: \mathrm{CO}_{2}$ concentration distribution at three sizes of obstruction is shown in Fig. 5. As shown in (Fig. 5a) maximum $\mathrm{CO}_{2}$ concentration in case- 1 is near the adjacent zone from obstruction faces. The concentration of $\mathrm{CO}_{2}$ in the upper zone of the room is minimum due to higher ventilation rate in comparison with the other zones in the room. Figure $5 \mathrm{~b}$ for case- 2 shows maximum value of $\mathrm{CO}_{2}$ concentration near the left and top faces of the 
obstruction. Cold jet of air strikes the east wall and forms recirculation zone between east wall and right face of the obstruction. Thus $\mathrm{CO}_{2}$ concentration reduces in this zone. Figure $5 \mathrm{c}$ shows $\mathrm{CO}_{2}$ concentration for case-3. It has maximum value at the top and left face of the obstruction; this is because the flow is not affecting these faces. Concentration of $\mathrm{CO}_{2}$ in the zone between east wall and right face of obstruction is less than in the pervious cases- 1 and 2 due to reduction in the size of obstruction. Figure 6 shows $\mathrm{CO}_{2}$ concentration distribution with three size of obstruction on central plane at $\mathrm{Y}=1.8 \mathrm{~m}$.

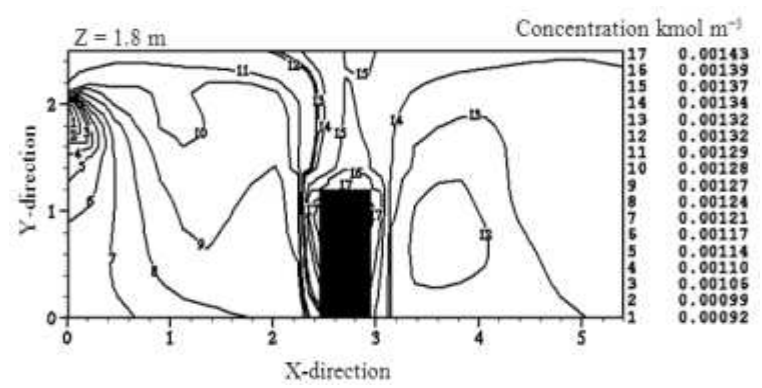

(a)

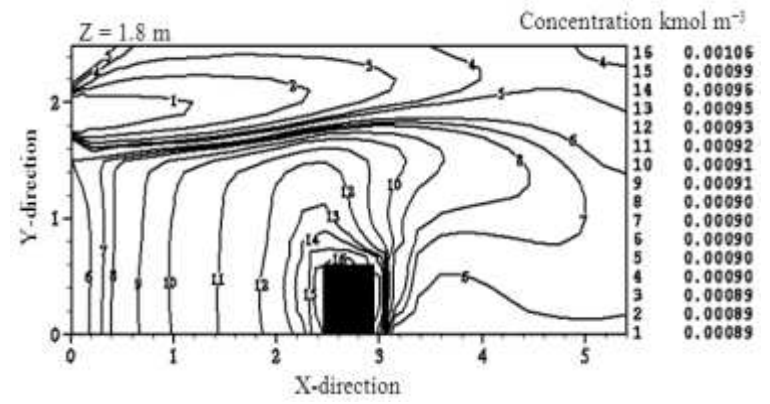

(b)

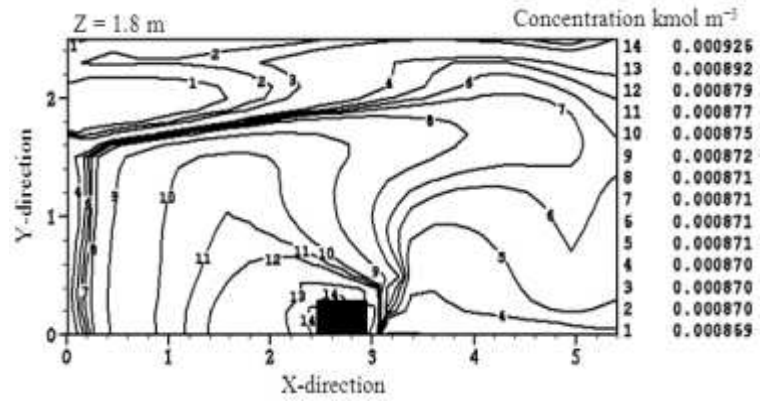

(c)

Fig. 5: $\mathrm{CO}_{2}$ concentration distribution according to changing size of obstruction in $x-y$ plane at $\mathrm{z}=1.8\left(\mathrm{kmol} \mathrm{m}^{-3}\right)$ : (a) case-1 (b) case-2; (c) case-3
For case- 3 the $\mathrm{CO}_{2}$ concentrations is lower than case- 2 and case- 1 and the maximum value is seen above the top face of obstruction.

Effectiveness of ventilation (thermal): Ventilation (temperature) efficiencies for three different sizes of obstruction are shown in Fig/ 7. It is seen that ventilation (temperature) efficiency increases with decrease in size of obstruction.

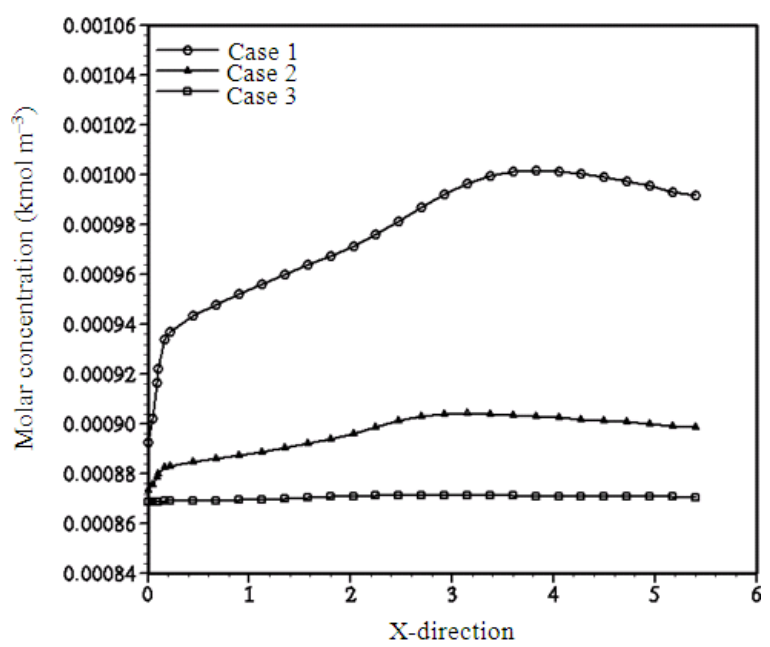

Fig. 6: $\mathrm{CO}_{2}$ concentration distribution in $\mathrm{x}-\mathrm{y}$ plane at $\mathrm{Y}=1.8 \mathrm{~m}$ with variation of size of obstruction

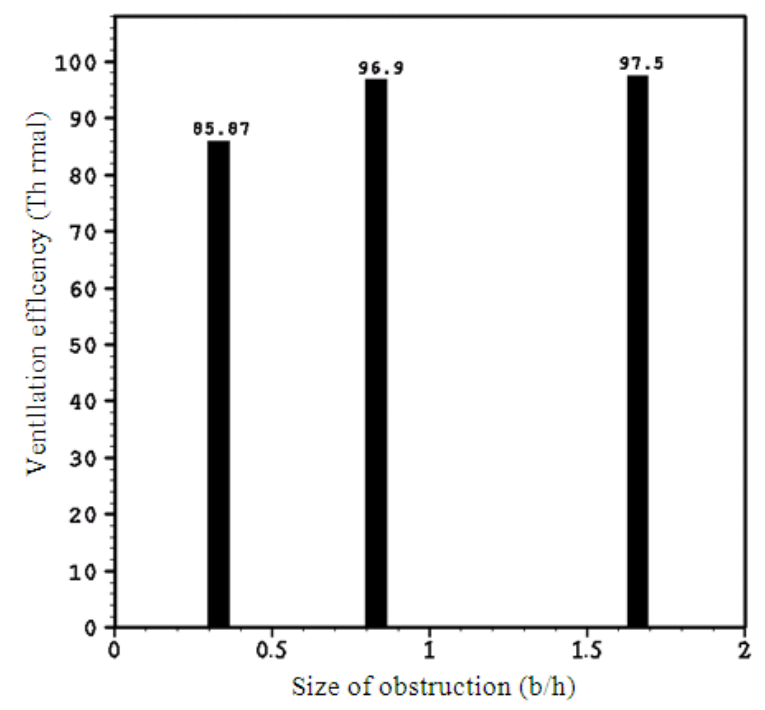

Fig. 7: Ventilation efficiency (thermal) with variation of size of obstruction 
Am. J. Engg. \& Applied Sci., 3 (2): 372-379, 2010

\section{DISCUSSION}

Investigation and analysis of the flow field, temperature and $\mathrm{CO}_{2}$ concentration distributions in three cases according to sizes of obstruction inside the room which has heat flux $116 \mathrm{~W} \mathrm{~m}^{-2}$ have been done by using the numerical method at constant air flow rate. Sizes of obstruction investigated $\mathrm{b} / \mathrm{h}$ are $0.42,0.83$ and 1.66. Value of air flow rates is $14.70 \mathrm{~m}^{3} \min ^{-1}(18.5$ $\mathrm{ACH})$.

The room temperatures of floor, ceiling, north, south, east and west wall are $297 \mathrm{~K}, 297.5 \mathrm{~K}, 296.5$, 297.5, 296 and $297.5 \mathrm{~K}$ respectively. (k- $\varepsilon$ ) turbulence model is employed to predict the indoor airflow. These values and inlet temperature are taken from an elementary analysis of the characteristics of indoor air flow summarized in ( $\mathrm{Li}, 1992)$ and include estimated thermal and flow ranges in rooms.

The velocity of air is low in the occupation zone while in the upper zone is higher due to use mixing ventilation. Range of Temperature distribution is 293.76-300.50 K in case 1 while reduce in case 2 to range 293.55-298.41 $\mathrm{K}$ and reach in case 3 to 293.53$296.86 \mathrm{~K}$ because of presence obstruction with different sizes at same inlet velocity. Commonly, local and average Nusselt numbers, $\mathrm{Nu}_{\mathrm{L}}$ and $\mathrm{Nu}$, should be used to evaluate the convective heat transfer. Convective heat transfer is higher when nusselt number is lower.

The rate of production of carbon dioxide, $\mathrm{G}$ is related to the metabolic rate and body surface by the equation (Awbi, 1991):

$$
\mathrm{G}=4 \times 10^{-5} \mathrm{M} \mathrm{A}
$$

Where:

$\mathrm{G}=\mathrm{CO}_{2}$ production, $1 \mathrm{sec}^{-1}$

$\mathrm{M}=$ Metabolic rate, $\mathrm{W} \mathrm{m}^{-2}$

$\mathrm{A}=$ body surface area, $\mathrm{m}^{2}$

Body surface has changed according to three sizes of obstruction that lead to variation production of $\mathrm{CO}_{2}$. Select of ventilation rate depend on this production. The ventilation efficiency (temperature efficiency) can be defined as follows:

$$
\mathrm{E}_{\mathrm{T}}=\frac{\mathrm{T}_{\mathrm{e}}-\mathrm{T}_{\mathrm{i}}}{\mathrm{T}_{\mathrm{av}}-\mathrm{T}_{\mathrm{i}}}
$$

Where:

$\mathrm{T}_{\mathrm{i}}, \mathrm{T}_{\mathrm{av}}, \mathrm{T}_{\mathrm{e}}=$ Supply air temperature, average indoor air temperature and exhaust air temperature

$\mathrm{E}_{\mathrm{T}} \quad=$ Called the energy usage coefficient
Ventilation of efficiency is higher when the obstruction is small size and vice versa depends on the difference between average and inlet air temperature.

\section{CONCLUSION}

In this study the airflow characteristics inside a room with an obstruction at three values of size of obstruction have been investigated using CFD simulation. Further, the effect of the size of obstruction on ventilation performance was studied on flow field, temperature distribution and $\mathrm{CO}_{2}$ concentration. Distribution of temperature is non-uniform. Energy usage coefficient is increasing with increase in size of obstruction. Average Nusselt number for the top face of obstruction is increase with decrease size of obstruction depend on convective heat transfer. The temperature distribution is minimum in all the three cases near the inlet opening and maximum near the obstruction. Increments of the size of obstruction cause increments in the $\mathrm{CO}_{2}$ concentration and have relatively large energy consumption.

\section{REFERENCES}

Awbi, H.B., 1989. Application of computational fluid dynamics in room ventilation. Build. Environ., 24: 73-84. DOI: 10.1016/0360-1323(89)90018-8

Awbi, H.B., 1991. Ventilation of Buildings. First Published, E and FN Spon, London, ISBN: 0-41915690-9, pp: 3 .

Craven, B.A. and G.S. Settles, 2006. A computational and experimental investigation of the human thermal plume. J. Fluids Eng., 128: 1251-1258. DOI: $10.1115 / 1.2353274$

Chen, C.L. and C.H. Cheng, 2006. Numerical study of flow and thermal behavior of lid-driven flows in cavities of small aspect ratios. Int. J. Numer. Methods Fluids, 52: 785-799. DOI: 10.1002/_d.1203

Fluent Inc., 2006. Fluent 6.3. User's Guide. http://www.filestube.com/f8cd132eb0ffdfd903ea,g/ FLUENT-6-3-Tutorial-Guide.html

Gosman A.D., P.V. Nielsen A. Restivo and J.H. Whitelaw,1980. The flow properties of rooms with small ventilation openings. ASME, J. Fluids Eng., 102: 316-323. DOI:10.1115/1.3240688

Hadidi, B.M., 1998. Computational study of flow in mechanically ventilated space. MSc Thesis, Department of Aerodynamics, Faculty of Engineering Cairo University, pp: 53.

Li, Y., 1992. Simulation of flow and heat transfer in ventilated rooms. $\mathrm{Ph}$. D. Thesis, Department of Mechanics/Applied Computational Fluid Dynamics, Royal Institute of Technology, Sweden. 
Moureh J. and D. Flick, 2005. Airflow characteristics within a slot-ventilated enclosure. Int. J. Heat Fluid Flow, 26: 12-24. 10.1016/j.ijheatfluidflow.2004.05.018

Rees, J.J. and P. McGuirk, 2001. Numerical investigation of transient buoyant flow in a room with a displacement ventilation and chilled ceiling system. Int. J. Heat Mass Trans., 44: 3067-3080. DOI: 10.1016/S0017-9310(00)00348-3

Tain, Z.F., J.Y. Tu, G.H. Yeoh and R.K.K. Yuen, 2007. Numerical studies of indoor airflow and particle desperation by large eddy simulation. Build. Environ., 42: 3483-2492. DOI: 10.1016/j.buildenv.2006.10.047
Wang, S.K. and Z. Lavan, 1999. Air-Conditioning and Refrigeration. Frank Kreith Boca Raton, CRC Press LLC, pp: 9-2.

Zou Yue, D., 1999. Air Jet Velocity Decay in Ventilation Applications. Building Services Engineering Royal Institute of Technology (KTH), Stockholm, Sweden, pp: 15. 